\title{
Methodologies for conducting research in an indigenous context
}

\author{
Spencer C. Lilley
}

\begin{abstract}
This article introduces researchers in the library and information sciences to indigenous research methods by describing the context of indigenous peoples and how their indigeneity is defined. An outline of why these methods have been developed and examples of how they have applied in indigenous research contexts, including an explanation of why these methodologies are important and a description of a series of guiding principles, and how the methods can be applied in indigenous research settings. An important aspect of the article is the consideration of whether non-indigenous researchers can be effective users of the methodologies outlined. The use of indigenous research methods in New Zealand through kaupapa Māori methods is provided as a case study.
\end{abstract}

\section{Introduction}

Research studies in library and information studies have traditionally relied on methods that are quantitative, qualitative or a combination of the two. Other methods that are used

\section{Authors \\ Spencer Lilley (Te Atiawa) is a Senior Lecturer (Māori Education) at Massey University in New Zealand.}

Email: $\underline{\text { s.c.lilley@massey.ac.nz }}$ 
frequently include content analysis, and the application of citation analysis, whether it be in the form of scientrometrics, altmetrics or bibliometrics. Although indigenous research methodologies are often applied in other disciplines in the social sciences, they are not at all prominent in the research literature of the library and information sciences. However, there is an increased focus on indigenous activities at the international level in associations such as the International Federation of Library Associations (IFLA) and the International Indigenous Librarians Forum (IILF), and a growing consciousness within countries with indigenous populations that these groups have specific resource and service needs. This increased interest needs to be augmented by a corresponding rise in research activity so the library and information profession can gain a stronger understanding of what is required to improve the access of indigenous peoples to information needs and how to deliver services that will result in equitable outcomes. The purpose of this paper is to introduce readers to indigenous research methods, define what they are, why they are important, how they are applied and who can apply them. Later in the paper an example is provided of how indigenous research methods are applied in New Zealand, where they are commonly referred to as kaupapa Māori methods.

\section{Defining Indigenous}

The issue of indigenous identity and who is indigenous can vary from one country to the next. Definitions of who is indigenous also vary, with no one statement taking precedence over another. This can lead to a situation where defining who can identify as indigenous is viewed as being politically and socially contentious within some territories. This is due to the fact that indigeneity and membership of indigenous groups is, in some cases, set in 
legislation, for example The Indian Act 1985, in Canada. This Act is otherwise known as Bill C-31, which ultimately controls an individual's rights to have their Indian status officially recognised while at the same time determining whether they qualify for band membership (Lawrence, 2004). In New Zealand, although a Māori is defined as "a member of the Māori race and includes any descendant of such a person” (Te Ture Whenua Māori Act, 1993), individuals must have their whakapapa (ancestry) authenticated before they become eligible to have their status as members recognised by their iwi (tribal grouping). This is essential for those wishing to benefit from the compensation settlements that their iwi have received from the New Zealand government for breaches of the Treaty of Waitangi.

The lack of a universally accepted global statement contributes to this situation There is no defining statement from the United Nations in the Declaration of the Rights of Indigenous Peoples having been adopted in 2008; although Article 33 of the Declaration does state that "Indigenous peoples have the right to determine their own identity or membership in accordance with their customs and traditions". There has, however, been a definition provided by the United Nations Educational, Scientific and Cultural Organization (UNESCO draft glossary, 2002); those that are indigenous are "a group, community or custom that is generally considered to belong to a certain region or country and which cannot be shown to have originated elsewhere." Indigenous people are defined as "a group of people belonging to a certain country or region which is distinguished from other groups by language, customs and attitudes."

The definition that is used as a guideline by the International Indigenous Librarians' Forum is that indigenous people are "those who have become minority peoples in their place 
of cultural origin.” (International Indigenous Librarians' Forum, 2009). This definition of course is not inclusive, and actively excludes indigenous populations in Asia, Africa, South America and many of the original peoples of the Pacific. A more inclusive definition is provided by Roy (2016), who surveys the definitions of indigeneity as they have been applied internationally and within indigenous communities within countries. Roy's concluding sentence in this work paraphrases a definition provided by Pack (2012) and states that “indigenous communities know who their people are" (Roy, 2016: 23). This indicates that, from an indigenous perspective, non-indigenous agencies and organisations should refrain from defining and determining who is indigenous, and leave it to the indigenous communities themselves to decide.

\section{Indigenous research methods}

In her critically acclaimed text on decolonizing methodologies, Māori scholar Linda Tuhiwai Smith $(1999,2012)$ identifies the term 'research' as being a dirty word in indigenous communities. This is due to the perception by indigenous peoples that they have for centuries been the focus of researchers schooled in, and applying, methods that reflect western scientific traditions. These methods are perceived as being steeped in the frameworks of colonialism and imperialism, with no actual benefits for the indigenous communities that have been the subject of the research conducted. Researchers have instead been perceived as exploiting indigenous participants for their own gain, and to receive recognition within their own academic communities by attaining higher qualifications, promotions and royalties from their endeavours. 
Generally speaking, there is not one form of indigenous research methodologies that can be applied. This is because indigenous populations globally are extremely diverse, culturally, socially, linguistically and politically. Within country boundaries, such as the United States of America, each tribal group of Native Americans have their own values, social structures, languages and knowledge systems that are unique to them as a people. The point of these explanations is to show that this diversity and difference between peoples requires an approach that is congruent with the specific values and cultural protocols shared and practiced by the community being researched. However, there are some broad guidelines that could act as an aid to researchers wishing to undertake research within an indigenous community. One of the first steps should involve reading and understanding the literature that is available on indigenous research methods. In addition to Smith's seminal work (1999, 2012), other useful items to consult are Bishop (1994, 1998), Brayboy (2000), Wilson (2001, 2008), Kovach (2009), Denzin, Lincoln \& Smith (2008) and Archibald, (2008). These works are all by experienced scholars, and describe the challenges and expectations faced by researchers wishing to engage in indigenous research. They also help emphasise the role that the community being researched has in determining the terms of engagement, and the level of access to their members and the knowledge that they hold.

Prior to embarking on a research project, researchers must establish a strong relationship with the community they want to work with. This requires the researcher to become an active participant in the community when appropriate. This connection should not last for the duration of the project only; there should be an intention to develop an ongoing relationship. Critical to the success of any research project with indigenous communities is 
that the first beneficiaries must be the community that is involved in the research. Part of this process is for the researcher to be open about their own background, who they are, where they are from, and what has influenced their lives and developments as a person and as a researcher. This is what is commonly referred to in the literature (Bishop, 2005; Lomawaima, 2000; Smith, 2005; Wilson, 2008) as a researcher 'locating' themselves. It provides the community with an opportunity to understand the researcher's prior experience, commitment to indigenous issues, and whether their philosophical outlook has a particular bias that will impact on their approach to the research and their relationship with the community.

Another guiding principle is about what is researched. Some indigenous communities may have already been the subject of numerous research projects, however the research that was conducted might not have been in areas that proved useful to their needs. Through negotiation with elders and other advisors within a community, researchers should be able to identify a project that is going to result in outcomes that benefit that particular community.

There also needs to be an agreement about the ownership of the research, and whether there are any limitations on how and where the information can be disseminated or published. This is particularly important when considering the issues of ongoing cultural and intellectual property rights, and issues around acknowledgement of the contribution by community members if items are published, especially if there are royalties that result from this.

Another critical aspect of the research relates to the ethical processes that must be followed, particularly the negation or diminution of any power relationships, which may otherwise lead to community members feeling coerced or obliged to participate in the project. 
If the university or institution that a researcher is affiliated to has a code of ethics for research involving human participants, this needs to be checked for any specific requirements for conducting research in indigenous contexts. Guidelines for conducting ethical research with Māori were developed by Te Awekotuku, (1991), and these have been taken up and applied by universities and funding agencies in New Zealand. For instance, in the Code of ethical conduct for research, teaching and evaluations involving human participants at Massey University in New Zealand (Massey University, 2015), academics and students undertaking research with Māori are expected to be familiar with the specific expectations associated with the Treaty of Waitangi. These relate to participation, protection and partnership, including recognition of the important role that tikanga Māori, cultural values and te reo Māori have in the organisation and transmission of knowledge.

If a researcher is from outside the community, or is inexperienced in conducting research, another useful initiative is to propose that the project be informed by an advisory group. This is in keeping with negotiating 'tricky ground', as outlined by Smith (2005), and is as much about protecting the researcher as it is about safeguarding the community.

Decisions about the composition of this group should be made in partnership with representatives of the community itself, rather than in isolation. This is a critical issue to get right, as this group will not only provide useful guidance and having their support will provide ease of access to community participants. However, if the group is established but not engaged with, or their advice is unnecessarily ignored, the research project could fail. If the research involves inter-personal interviews or focus group sessions, it would be advisable for these to take place in the community itself, as this is possibly a place where participants 
would feel more comfortable. This could be in a cultural centre, or another community facility such as a library or school. The important thing here is to ensure that the sessions can be conducted in a confidential manner, if required. Even if the results do not name individuals, these communities can be tight-knit and anonymity cannot always be handled as discreetly as it can in other locations. It is not uncommon for everyone to know when the researcher is present in the community and who they are talking to, so retaining a sense of privacy is often a challenging proposition.

Although indigenous research methods are often qualitatively focused, it is possible to conduct quantitative studies as well. It is preferable that the latter also includes a qualitative phase as well, resulting in a mixed methods project. The administering of a quantitative instrument allows data to be gathered more quickly and in greater numbers, and where the results are statistically valid they can be used to generalise beyond the responding participants. One of the major disadvantages of using a quantitative instrument is that it can make it difficult for researchers to be personally known to the participants in the research, which could result in a low return rate. Using a qualitative approach enables researchers to develop a strong relationship with the community participating in the research, allows probing questions, and typically involves fewer participants. However, one of the major disadvantages is that the results are not able to be generalised to the broader population.

The process of gathering data and the subsequent storage, transcription and analysing of it provide further challenges for those with little experience in conducting research within an indigenous framework. In some instances, participants may not want to be recorded, and this will require the interviewers to take comprehensive notes. Others who agree to be 
recorded may also require the recording to be returned to them or deleted after the transcription has taken place. At various times during the interview or focus group discussions, information may be shared that participants want to exclude from the transcript used for data analysis. This process can normally be facilitated through interviewees having the draft transcripts returned to them for editing and, where necessary, exercising their right of veto over the contents. As the rightful owners of the knowledge shared in the interviews, they may decide to partially or completely withdraw the transcript from the research project.

Analysis of the data involves one of the most vital elements of the research project. Research on indigenous communities that has been conducted in a western research tradition has tended to not only have disregarded the needs of the community, but has also tended to mean that the data has been analysed using a lens that does not reflect the worldview of the indigenous community that it has been collected from. This is illustrated by the first four chapters in Decolonizing methodologies, (Smith, 2012), where she provides a commentary and critique of the research conducted on indigenous peoples by western individuals and institutions from the early explorers (from Columbus onwards), aspiring imperial authorities and colonising powers.

For non-indigenous researchers, being able to contextualise knowledge in a worldview that is not familiar to them can be problematic and may result in important data being overlooked or misinterpreted. One solution for this is to include an indigenous researcher, preferably from the actual community being researched, who possesses the cultural and linguistic knowledge necessary to help guide the analysis of data. Even those researchers who identify as indigenous (but are from other communities) can benefit from 
having a local researcher on their team. This person could not only help with facilitating the smooth passage of the research project, but would be invaluable in the process of analysing the data using a lens that is conversant with the values, beliefs, customs, behaviours and knowledge that forms the core elements of their worldview. This is particularly important when analysing data that has been expressed in an indigenous language. Without such a lens or an intimate knowledge of the language, Kovach (2009), Ermine (1995), Smith (2012) all question the value of the analysis of indigenous data where the researcher lacks the skills or knowledge of the prevailing worldview of those being researched. The most likely outcomes would be a lack of a critical awareness of the cultural nuances of the data, possibly leading to lost opportunities and findings that do not accurately reflect the knowledge that has been shared.

\section{Library and information research on indigenous issues}

As an indigenous person, who has strong affiliations to three iwi (Māori tribal groups), the author is one of a very limited number of indigenous scholars conducting research on indigenous library and information matters. A recent study (Lilley, 2017) identified that the number and impact of articles about indigenous issues in the library and information sciences is very low. This study also revealed that a vast majority of this literature was focused on professional and practice related matters rather than resulting from research projects. The low impact of these articles was further demonstrated by the small number of citations for these articles, with only sixteen out of the 178 analysed articles receiving five or more citations. A substantial amount of the published literature on research in this field has been done by non-indigenous peoples, or in collaboration between indigenous 
and non-indigenous researchers. This could be viewed as evidence of the low numbers of indigenous scholars and researchers operating in the library and information sciences discipline.

It also appears that the use of indigenous methods in the research projects that led to the articles was very minor. Further research needs to be conducted to ascertain why such methods have not been utilised, other than there being a very low number of active indigenous researchers in the discipline. The interest shown by non-indigenous researchers demonstrates that indigenous issues is an area of increasing importance to the library and information science communities.

\section{The role of non-indigenous researchers}

With increased calls for the self-determination of their own affairs by indigenous peoples worldwide, it comes as no surprise that there are some that believe that indigenous research should only be done by indigenous researchers. Smith (2012, pp. 186-187) poses the questions, “can a non-indigenous researcher carry out kaupapa Māori research?” Her answer comes in two forms, with the more conventional stating "a non-indigenous, non-Māori person can be involved in kaupapa Māori research, but not on their own; and if they were involved in such research, they would have ways of positioning themselves as a non-indigenous person." What she terms as the more "radical rejoinder" to the question is, "by definition, no: kaupapa Māori research is Māori research exclusively." However, if the phrase indigenous research were substituted for kaupapa Māori, then such an answer would be very restrictive. This was clearly demonstrated in the last section, where we saw that in the library and information sciences this would result in very little research in this important area being undertaken. 
One of the critical challenges for non-indigenous researchers will be to recognise and capture the 'indigenous voice' of their respondents. This is where the principle of partnership becomes important, and where an experienced non-indigenous researcher can form a strong union with an indigenous researcher. The terms of such a union are important, because even if the non-indigenous person is more experienced, they will at times have to understand that in some aspects of their involvement they will have to assume a minor role. Their relationship with their indigenous research partner would preferably be recognised as one of reciprocity, rather than being exploitative. This would involve developing the capacity of the indigenous team member/s to be more effective researchers; in return, the non-indigenous researcher would receive access to, and have more legitimacy in the community, and would see the data collected being further enriched through the application of the indigenous lens.

\section{Indigenous methodologies in the New Zealand context}

Māori focused methodologies emerged in New Zealand in the 1990s through the work of Māori scholar, Professor Graham Hingangaroa Smith, (cited in Smith, 2012, p. 187) who drew on and applied the principles of critical theory to knowledge being created in a Māori context. This resulted in the development of a framework which he named kaupapa Māori theory. This theoretical framework, when applied as a research methodology, was seen by Smith as a desire by Māori for self-determination in wider New Zealand society. His summary of the value of such a research focus is framed by it being:

\section{Related to being Māori;}

2. Is connected to Māori philosophy and principles; 
3. Takes for granted the validity and legitimacy of Māori, the importance of Mãori language and culture;

4. Is concerned with the struggle for autonomy over our own well-being.

The framework for the methodologies have been enhanced by being applied to a wide variety of research projects in social sciences, health, education and Māori studies. The methodology is now commonly referred to kaupapa Māori research (research with a Māori focus). Smith's original framework consisted of six principles, with principles seven and eight (in the following list) added by Pihama (2001) and Pohatu (2004) respectively. The head titles for these principles are as follows (more information about each is available from the webpage listed in the references):

1. Tino Rangatiratanga - The Principle of Self-determination

2. Tāonga Tuku Iho - The Principle of Cultural Aspiration

3. Ako Māori - The Principle of Culturally Preferred Pedagogy

4. Kia piki ake i ngā raruraru o te kainga-The Principle of Socio-Economic Mediation

5. Whānau - The Principle of Extended Family Structure

6. Kaupapa - The Principle of Collective Philosophy

7. Te Tiriti o Waitangi - The Principle of the Treaty of Waitangi

8. Ata - The Principle of Growing Respectful Relationships

(Rangahau, n.d.) 
The application of these principles to a Māori research context is not restrictive, as there is a recognition that the community being researched will have their own expectations about how they engage with the project. These expectations will be managed and determined by tikanga Māori (Māori customs) or kawa (protocols), (te reo Māori terms are also included in a glossary at the conclusion of this article). Although there are some common aspects to these protocols and customs from one iwi (tribal group) to the next. There are also practices that are unique to each iwi, and it is essential researchers understand how these variations might impact on their project and their relationship with the community they are working with.

Guidelines for ethical practices involving research with Māori are a feature of most universities and other research institutions and are linked to principles that have been agreed to in the Treaty of Waitangi. The Treaty was an agreement that was signed in 1840 between the British Crown and Māori rangatira (chiefs), which sets the standard for how Māori and non-Māori engage in a bicultural partnership. The ethics of this engagement process with Māori communities focuses heavily on informed consent. This can often involve gaining the approval of kaumatua (elders) to proceed with the research or having it discussed in a hui (meeting) of the community.

Critical to having the project endorsed is for researchers to be known to the community. If they are an active member of this community, then this is straightforward as they should be known. For Māori that are from another community or for non-Māori, this will involve identifying who you are, where you are from, who your iwi is (if applicable) and what prior experience you have had with undertaking research with Māori. This information 
is further strengthened by identifying the purpose of the request, what will be done, why and what for, and a detailed explanation of how it will benefit the community. The composition of the community will not always be tribal, as there are other contexts in which Māori research is undertaken, including an organisation, institution or social grouping. This could involve different pathways to gaining consent. However, if the organisation that is being negotiated with has a strong Māori presence, they will in all likelihood have a tikanga in place for dealing with research requests.

For example research conducted within secondary schools that had a high percentage of Māori students on their rolls, had to follow a very strict consent process. This included meeting with the principal of each school to gain their consent to approach the Board of Trustees (governance board), and with the school whanau committee to gain their consent to undertake the research in their school. In one instance, at a church based school, the Board of Proprietors had to be met with and their consent gained.

After completing the consultation with the each of the schools' leadership structures, it was then permissable to approach the students at each of the schools. Further consent was then sought from each participant, with active steps taken to ensure that the anonymity of students was preserved when the questionnaire was administered.

By arrangement with the principal of each school, a hui was convened for all students identified as eligible and available to participate in the project. This provided an opportunity to go through the research project, including discussing the 'what why, how, where and when' with them. However, before doing this, in keeping with protocol, a mihi (greeting) was delivered to them firstly in te reo Māori (Māori language) and then in English, which 
assisted in legitimising the researcher's status as a Māori researcher and secondly acknowledged the students and their affiliations to whanau (extended family), hapū (subtribal grouping) and iwi. This was followed by a karakia (incantation) and an opportunity for the students to ask questions, or seek further clarification about the process.

As part of the same project, focus group discussions were conducted at each of the four schools involved in the research. These sessions followed a similar format to the hui where the questionnaire had been administered. However, as they involved fewer participants than had attended the hui, the aspects of tikanga Māori used were less formal, with an emphasis on mihi mihi (short introductions) so that all participants, including myself, were informed about the background of all in attendance. This was followed by a karakia and the sharing of kai (food). These last two acts are important for moving a setting from being tapu (sacred) to the state of noa (safety), where the participants and I could mix freely and discuss matters in a less formal manner.

Following a more casual form of tikanga enabled each student to be more relaxed and comfortable about speaking in a group situation. Few ground rules were set for the discussion, other than respecting the opinions of others and not talking over the top of each other. Participants were also informed that they could speak in te reo Māori if that made them feel more comfortable. The quieter members of the focus groups were also encouraged to give their opinion throughout the session.

The analysis of the questionnaire and focus group data was themed using a framework that was based on mātauranga Māori (Māori knowledge systems) values. One of the more important aspects of the kaupapa Māori research process is to ensure that there are benefits 
for the community and a culture of giving back. In this instance, detailed written feedback was provided to each school about how the data collected from their students could be used to assist Māori students to broaden and develop their information behaviour skills. In addition, an offer was made to discuss the report and its implications with staff and students at each of the schools; this was an effective way of returning benefits to the community.

\section{Conclusion}

This article has provided a conceptual summary of the characteristics of indigenous research methods, including how they can be used in library and information science research to improve outcomes for indigenous communities. The article has contextualised how indigenous research methods have been applied within New Zealand using kaupapa Māori theory. It also emphasises the critical role that indigenous methodologies have in ensuring that the benefits of any research being conducted within indigenous contexts is the community itself. It also stresses that culturally appropriate approaches should be at the forefront of the research activities being undertaken.

The increased interest in international indigenous matters within the library and information professions has yet to be reflected in the research activity. Although there is some thought that indigenous research should only be undertaken by indigenous persons, the reality in the library and information profession is that there are insufficient researchers of indigenous descent working in this field. Any growth in the number of indigenous researchers within the library and information management studies disciplines is likely to be a slow process. One way that non-indigenous researchers can assist in this process is to actively seek partnerships with indigenous students and information professionals who are 
interested in research, and embark on critical research that assists in defining and meeting the information needs of indigenous communities. Another option could involve reaching an agreement to provide an opportunity for community members to become skilled in undertaking research. Inexperienced non-indigenous researchers wishing to take up research in an indigenous community should seek guidance from elders, institutional ethical codes, and from researchers with substantial experience in this particular field. This article will hopefully act as a spur to experienced or potential researchers that wish to make a difference in an emerging and very important area of research. 


\section{Glossary of Māori words and phrases}

Ako Māori

Ata

Hapū

Hui

Iwi

Kai

Karakia

Kaumatua

Kaupapa Māori

Kawa

Kia piki ake i ngā

raruraru o te kainga

Mātauranga Māori

Mihi

Mihi mihi

Noa

Rangatira
Māori pedagogy

Growth of respectful relationships

Sub-tribal grouping

Meeting

Tribal grouping

Food

Incantation

Elder

Māori agenda

Protocols

Māori knowledge systems

Greeting

Short introductions

Safety (profane)

Chiefs 
Tāonga Tuku Iho

Tapu

Te Reo Māori

Te Tiriti o Waitangi

Tikanga Māori

Tino Rangatiratanga

Whakapapa

Whanau
Treasures that have been inherited

Sacred

Māori language

The Treaty of Waitangi

Māori

Self Determination

Ancestral links, genealogy

Extended family group

\section{References}

Archibald, J. (2008). Indigenous storywork: educating the heart, mind, body and spirit. Vancouver, BC.: UBC Press.

Bishop, R. (1998). Freeing ourselves from neo-colonial domination in research: A Māori approach to creating knowledge. International Journal of Qualitative Studies in Education, 11(2), 199-219.

Bishop, R. (1994). Initiating empowering research. New Zealand Journal of Educational Studies, 29(2), 175-188

Bishop, R. (2005). Freeing ourselves from neo-colonial domination in research: a kaupapa Māori approach to creating knowledge. In N. Denzin \& Y. Lincoln (Eds.). The Sage 
handbook of qualitative research (3rd ed., pp.109-138). Thousand Oaks: Sage Publications.

Brayboy, B. (2000). The Indian and the researcher: tales from the field. International Journal of Qualitative Studies in Education, 13(4), 415-426.

Denzin, N.; Lincoln, S. and Smith, L.T. (eds.) (2008). Handbook of indigenous and critical methodologies. Los Angeles: Sage.

Ermine, W. (1995). Aboriginal epistemology. In M. Battiste \& J. Barman (Eds.), First Nations education in Canada: The circle unfolds (pp.101-112.). Vancouver, BC: UBC Press

International Indigenous Librarians’ Forum. (2009) Retrieved from https://archive.trw.org.nz/iilf2009_programme.php\#attend

Kovach, M. (2009). Indigenous methodologies: characteristics, conversations, and contexts. Toronto, ONT: University of Toronto Press.

Lawrence, B. (2004). "Real” Indians and others: mixed-blood urban native peoples and indigenous nationhood. Vancouver, BC: UBC Press.

Lilley, S.C. (2017). Assessing the impact of indigenous research on the library and information studies literature. Information Research, 22(4) Retrieved from http://www.informationr.net/ir/22-4/rails/rails1606.html

Lomawaima, T.K. (2000). Tribal sovereigns: reframing research in American Indian education. Harvard Educational Review, 70(1), 1-23. 
Massey University (2015). Code of ethical conduct for research, teaching and evaluations involving human participants. Retrieved from http://www.massey.ac.nz/massey/research/research-ethics/human-ethics/code-ethical$\underline{\text { conduct.cfm }}$

Pack, S. (2012). What is a real indian? The interminable debate of cultural authenticity. AlterNative, 8(2), 176-188.

Pihama, L. (2001). Tihei mauri ora- Honouring our voices: Mana wahine as kaupapa Māori theoretical framework (Unpublished PhD thesis) University of Auckland, Auckland New Zealand.

Pohatu, T. (2004). Ata: growing respectful relationships. He Pukenga Korero 8(1), 1-8.

Rangahau (n.d.) Retrieved from: http://www.rangahau.co.nz

Roy, L. (2016). Who is indigenous? In C. Callison, L. Roy. And G. LeCheminant (Eds.), Indigenous notions of ownership and libraries, archives and museums (pp.7-24). Berlin: DeGruyter Saur Publishing.

Smith, L.T. (1999). Decolonizing methodologies: research and indigenous peoples. London, UK: Zed Books.

Smith, L.T. (2005). On tricky ground: researching the native in an age of uncertainty. In N. Denzin \& Y. Lincoln (Eds.), The Sage handbook of qualitative research (3rd ed., pp.85- 107). Thousand Oaks: Sage Publications

Smith, L.T. (2012). Decolonizing methodologies: research and indigenous peoples. $2^{\text {nd }}$ Ed. London, UK: Zed Books. 
Te Awekotuku, N. (1991). He tikanga whakaaro: research ethics in the Māori community. Wellington, N.Z.: Manatu Māori.

Te Ture Whenua Māori Act 1993. (2008) Retrieved from: http://www.legislation.govt.nz/act/public/1993/0004/latest/DLM289882.html

UNESCO Draft Glossary. (2002). Retrieved from: www.unesco.org/culture/ich/doc/src/00272-EN.doc

Wilson, S. (2001). What is indigenous research methodology? Canadian Journal of Native Education, 25(2), 175-179.

Wilson, S. (2008). Research is ceremony: indigenous research methods. Halifax, NS: Fernwood Publishing.

\section{Open access and copyright}

Library and Information Research is an open access journal. A freely available copy of this paper may be downloaded from the journal's website: http://lirgjournal.org.uk

Copyright and associated moral rights in works published in Library and Information Research are retained by the author(s) but this paper may be used freely, with proper attribution, in educational and other non-commercial settings. 